\title{
FORECASTING INDEKS HARGA SAHAM GABUNGAN (IHSG) DENGAN MENGGUNAKAN METODE ARIMA
}

\author{
${ }^{1)}$ Nurul Latifa Hadi \\ ${ }^{2)}$ Artanti Indrasetianingsih \\ ${ }^{1)}$ S1 Program Statistika, FMIPA, Universitas PGRI Adi Buana Surabaya \\ ${ }^{2)}$ Program Studi Statistika, FMIPA, Universitas PGRI Adi Buana Surabaya
}

\begin{abstract}
ABSTRAK
Salah satu indikator keberhasilan pembangunan adalah struktur ekonomi dan angka tabungan dalam hal perkembangan sector manufaktur atau industry. Kemajuan sektor usaha sendiri memerlukan dana investasi yang cukup besar untuk melakukan pengembangan-pengembangan usaha tersebut. Oleh sebab itu, peramalan (forecasting) terhadap harga return saham sangat berperan penting untuk memprediksi perkembangan harga dan return harga saham di masa yang akan dating. Berdasarkan latar belakang tersebut, penelitian ini dilakukan untuk meramalkan IHSG (Indeks Harga Saham Gabungan) dengan menggunakan metode ARIMA Box-Jenkins. Data yang digunakan adalah data harian IHSG periode Januari 2013 sampai Desember 2013. Berdasarkan hasil analisis dapat diketahui bahwa model ARIMA yang terbaik adalah ARIMA $(0,1,[1][12])$ karena mempunyai nilai MAPE $(1,30 \%)$, MSE $(3788,57)$ dan $\operatorname{AIC}(2484,6)$ yang terkecil.
\end{abstract}

Kata kunci : forecasting, ARIMA Box-Jenkins, IHSG

\section{Pendahuluan}

Menurut Tikson dalam Parsiyo (2005), salah satu indikator keberhasilan pembangunan adalah struktur ekonomi dan angka tabungan dalam hal perkembangan sektor manufaktur atau industri. Sehingga bisa disimpulkan bahwa, keberhasilan suatu negara dalam pembangunan dapat diamati dengan berkembangnya sektor usaha. Oleh karena itu, semakin meningkatnya aktivitas perdagangan atau usaha maka aktivitas ekonomi nasional akan semakin meningkat.

Kemajuan sektor usaha sendiri memerlukan dana investasi yang cukup besar untuk melakukan pengembangan-pengembangan usaha tersebut. Pasar modal merupakan salah satu sumber pembiayaan bagi dunia usaha dan wahana investasi bagi masyarakat atau pemilik modal. Menurut Munir dalam Astuti (2013), pasar modal merupakan suatu pasar dan dana-dana jangka panjang baik utang yang biasanya berbentuk obligasi maupun dana jangka panjang yang berbentuk saham yang diperdagangkan. Dalam setiap aktivitas penanaman modal, seorang investor akan senantiasa menaruh harapan akan mendapatkan manfaat dari penanaman modal tersebut. Semakin tinggi investasi yang ditanam, tentunya semakin tinggi pula hasil yang diharapkan, sehingga investor akan sangat berhati-hati dan penuh perhitungan ketika akan melakukan investasi. Oleh sebab itu, peramalan (forecasting) terhadap harga return saham, sangat berperan penting untuk memprediksi perkembangan harga dan return harga saham di masa yang akan datang. 
Berdasarkan latar belakang tersebut, maka pada penelitian ini dilakukan peramalan terhadap data IHSG (Indeks Harga Saham Gabungan) dengan menggunakan metode ARIMA Box-Jenkins. Data IHSG yang digunakan adalah data harian periode Januari 2013 sampai dengan Desember 2013. Tujuan dari penelitian ini adalah untuk mendapatkan model ARIMA yang sesuai untuk data IHSG dan untuk mendapatkan hasil peramalan (forecasting) data IHSG periode Januari 2014.

\section{ARIMA Box-Jenkins}

Menurut Makridakis, dkk. (1999), beberapa jenis model time series Box Jenkins (ARIMA) terdiri atas model Autoregressive (AR), Moving Average (MA), Autoregressive Moving Average (ARMA), dan Autoregressive Integrated Moving Average (ARIMA). Berikut ini penjelasan dari masing-masing model tersebut: Model Autoregressive (AR)

\section{a. Model Autoregressive (AR)}

Secara umum untuk model autoregressive orde ke-p (AR(p)), mempunyai bentuk sebagai berikut (Makridakis dkk., 1999):

Dengan :

$$
Z_{t}=\mu+\emptyset_{1} Z_{t-1}+\emptyset_{2} Z_{t-2}+\cdots+\emptyset_{p} Z_{t-p}+a_{t}
$$

$\mu \quad=$ nilai $\mathrm{konstan}$

$\emptyset_{p} \quad=$ parameter autoregressive ke-p

$a_{t} \quad=$ nilai kesalahan pada waktu ke-t

\section{b. Model Moving Average (MA)}

Model moving average umum berorde q (MA(q)) dapat ditulis sebagai berikut (Makridakis dkk., 1999):

$Z_{t}=\mu+a_{t}-\theta_{1} a_{t-1}-\theta_{2} a_{t-2}-\cdots-\theta_{q} a_{t-q}$

Dengan :

$$
\mu \quad=\text { nilai konstan }
$$

$\theta_{1}$ sampai $\theta_{q}=$ parameter moving average ke-q

$a_{t-q} \quad=$ nilai kesalahan pada saat $\mathrm{t}-\mathrm{q}$

\section{c. Model Autoregressive Moving Average (ARMA)}

Menurut Wei (2006), Model Autoregressive Moving Average merupakan model campuran dari model AR dan MA. Bentuk umum dari model umum ARMA $(\mathrm{p}, \mathrm{q})$ dapat ditulis dalam bentuk persamaan sebagai berikut :

Dengan :

$$
Z_{t}=\mu+\emptyset_{1} Z_{t-1}+\cdots+\emptyset_{p} Z_{t-p}+a_{t}-\theta_{1} a_{t-1}-\cdots-\theta_{q} a_{t-q}
$$

$$
\begin{array}{ll}
\emptyset_{p} & =\text { parameter autoregressive ke- } \mathrm{p} \\
\theta_{q} & =\text { parameter moving average ke-q } \\
a_{t} & =\text { nilai kesalahan pada waktu ke-t }
\end{array}
$$

\section{d. Model Autoregressive Integrated Moving Average (ARIMA)}

Model ARIMA (p,d,q) yang dikenalkan oleh Box dan Jenkins dengan orde $\mathrm{p}$ dari AR, orde d merupakan differencing, dan orde $\mathrm{q}$ dari MA. Bentuk persamaan model ARIMA adalah (Wei, 2006):

$$
\emptyset_{p} B \quad 1-B^{d} Z_{t}=\theta_{0}+\theta_{q}(B) a_{t}
$$


Dimana fungsi orde $\mathrm{p}$ dari AR yang telah stasioner:

$\emptyset_{p} B=\left(1-\emptyset_{1} B-\cdots-\emptyset_{p} B^{p}\right)$

Dan fungsi dari orde q dari MA yang telah stasioner:

$\theta_{p} B=\left(1-\theta_{1} B-\cdots-\theta_{p} B^{p}\right)$

Bentuk fungsi persamaan model ARIMA musiman adalah :

$\Phi_{p} B^{S} \emptyset_{p} B 1-B^{d}\left(1-B^{S}\right)^{D} Z_{t}=\theta_{q} B \Theta_{Q}\left(B^{S}\right) a_{t}$

Dimana :

$\Phi_{\mathrm{P}} \quad=$ orde $\mathrm{p}$ pada koefisien komponen AR musiman

$\emptyset_{p} \quad=$ orde $\mathrm{p}$ pada koefisien komponen $\mathrm{AR}$

$\Theta_{Q} \quad=$ orde $\mathrm{p}$ pada koefisien komponen MA musiman

$\theta_{q} \quad=$ orde $\mathrm{p}$ pada koefisien komponen MA

Model ini dinotassikan dengan ARIMA (p,d,q) $(P, D, Q)^{S}$ yang mempunyai faktor musiman dalam pengamatan waktu ke-t.

\section{Metodologi Penelitian}

Data yang digunakan pada penelitian ini adalah data IHSG harian periode Januari 2013 sampai Desember 2014 (www.duniainvestasi.com). Variabel yang digunakan pada penelitian ini adalah $z_{t}$, yaitu jumlah saham harian IHSG.

Metode analisis data dibagi menjadi dua bagaian, yaitu analisis deskriptif dengan tabel rata-rata dan varians per bulan, dan analisis model ARIMA BoxJenkins. Pada tahapan ini data penelitian dibagi dua, yaitu data in sample (periode Januari sampai Nopember 2013) dan data out sample (periode Desember 2013). Pemodelan ARIMA dilakukan dengan tahapan identifikasi model, pemeriksaan diagnostik, pemilihan model terbaik. Pemilihan model terbaik ditentukan dari nilai terkecil MAPE (Mean Absolute Percentage Error), MSE (Mean Square Error) dan AIC (Akaike's Information Criterion). Tahap selanjutnya adalah meramalkan satu periode ke depan (bulan Januari 2014).

\section{Hasil dan Pembahasan}

Hasil analisis deskriptif data IHSG dapat dilihat pada tabel 4.1. Dari tabel tersebut dapt diketahui bahwa rata-rata terbesar dari nilai harga saham IHSG terjadi pada bulan Mei $(5100,44)$, sedangkan rata-rata minimum dari nilai harga saham IHSG terjadi pada bulan Desember ( 4221,59). Varians terbesar terjadi pada bulan Agustus $(67929,4)$. Hal ini menunjukkan bahwa pada bulan agustus harga saham IHSG sangat beragam atau bervariasi nilainya.

Tabel 4.1 statistika deskriptif harga saham IHSG tahun 2013

\begin{tabular}{|l|l|l|}
\hline Bulan & Rata-rata & Varians \\
\hline Januari & 4403,12 & 1786,78 \\
\hline Februari & 4588,5 & 8023,78 \\
\hline Maret & 4823,16 & 2946,01 \\
\hline April & 4959,15 & 2036,54 \\
\hline Mei & 5100,44 & 5601,79 \\
\hline Juni & 4726,88 & 31272,9 \\
\hline
\end{tabular}




\begin{tabular}{|l|l|l|}
\hline Juli & 4631,38 & 9335,2 \\
\hline Agustus & 4345,16 & 67929,4 \\
\hline September & 4353,64 & 33188,3 \\
\hline Oktober & 4496,32 & 6097,32 \\
\hline November & 4359,72 & 6219,87 \\
\hline Desember & 4221,59 & 2264,41 \\
\hline
\end{tabular}

Pada tahapan analisis model ARIMA Box-Jenkins, langkah pertama adalah identifikasi model. Plot time series pada Gambar 4.1 menunjukkan bahwa data IHSG belum stasioner. Hal ini dapat dilihat dari Gambar 4.2a plot ACF, pada plot tersebut menunjukkan bahwa nilai berbeda secara signifikan dari nol dan mengecil secara perlahan, maka tidak stasioner dalam mean. Sedangkan untuk melihat stasioneritas dalam varians dapat diketahui dari transformasi box-cox, hasilnya dapat dilihat pada Gambar 4.2b yang menunjukkan bahwa nilai $\lambda$ antara 0,2 sampai 3,9. Karena pada selang tersebut memuat angka 1, maka data IHSG tidak perlu ditransformasi dan sudah stasioner dalam varians.

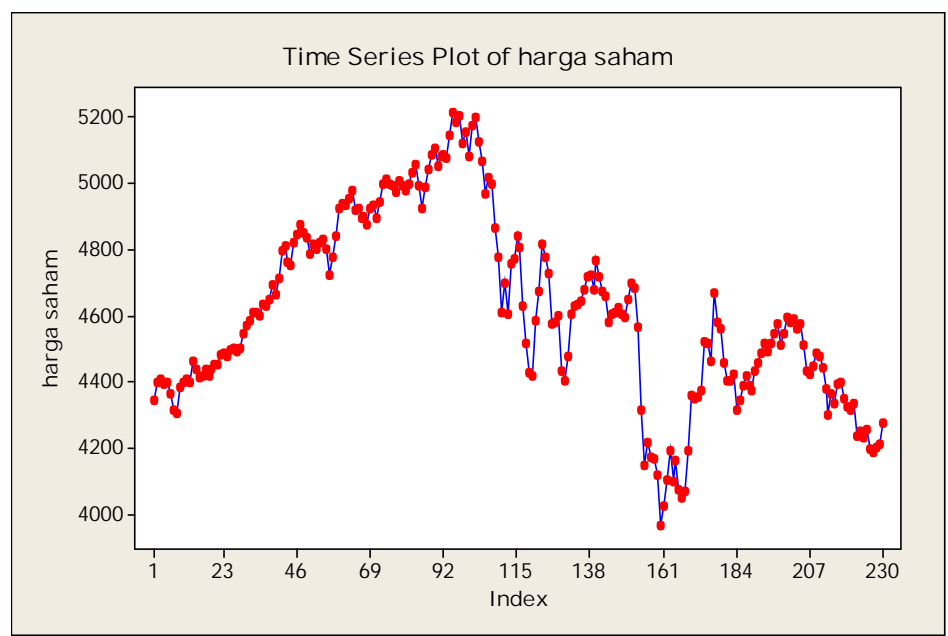

Gambar 4.1 Plot time series data IHSG

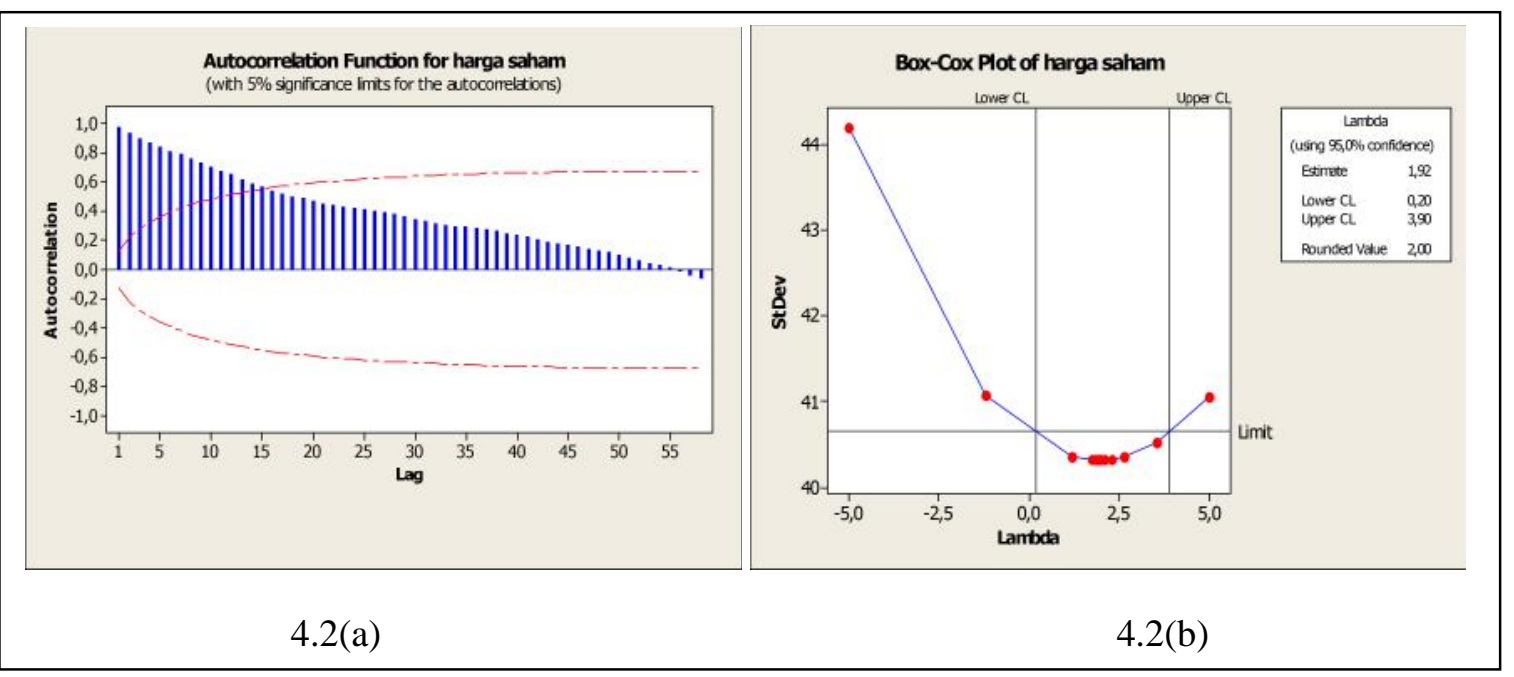

Gambar 4.2 Plot ACF dan Transformasi Box-Cox data IHSG 
Differencing 1 non musiman dilakukan untuk mengatsi data IHSG yang tidak stasioner dalam mean. Plot time series dan plot ACF setelah didifference 1 non musiman dapat dilihat pada Gambar 4.3 dan 4.4a. Pada gambar tersebut sudah menunjukan bahwa data sudah stasioner dalam mean.

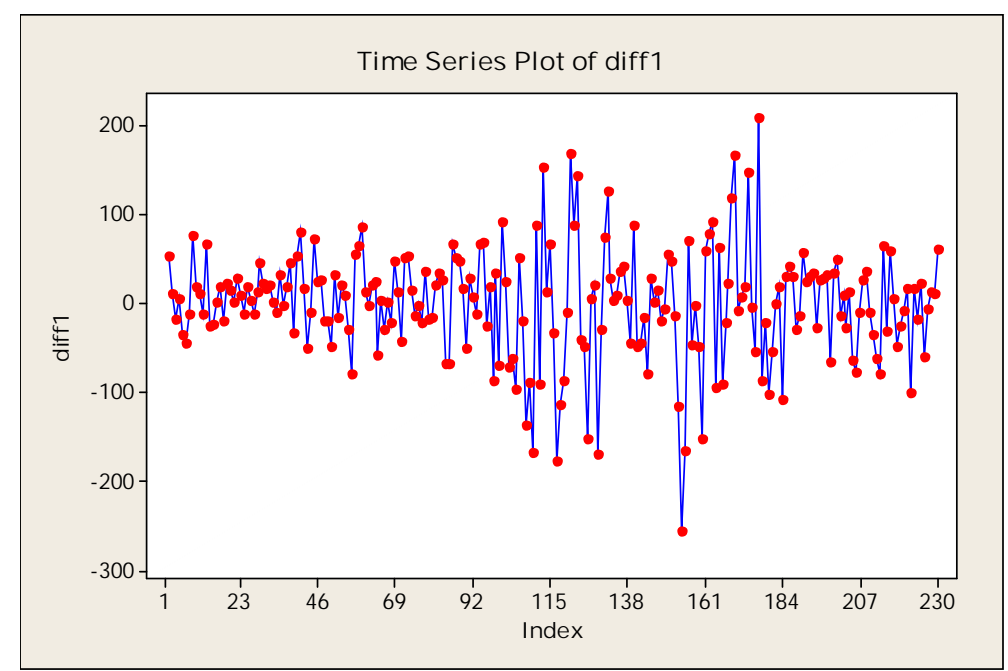

Gambar 4.3 Plot time series data IHSG setelah didifference 1 non musiman

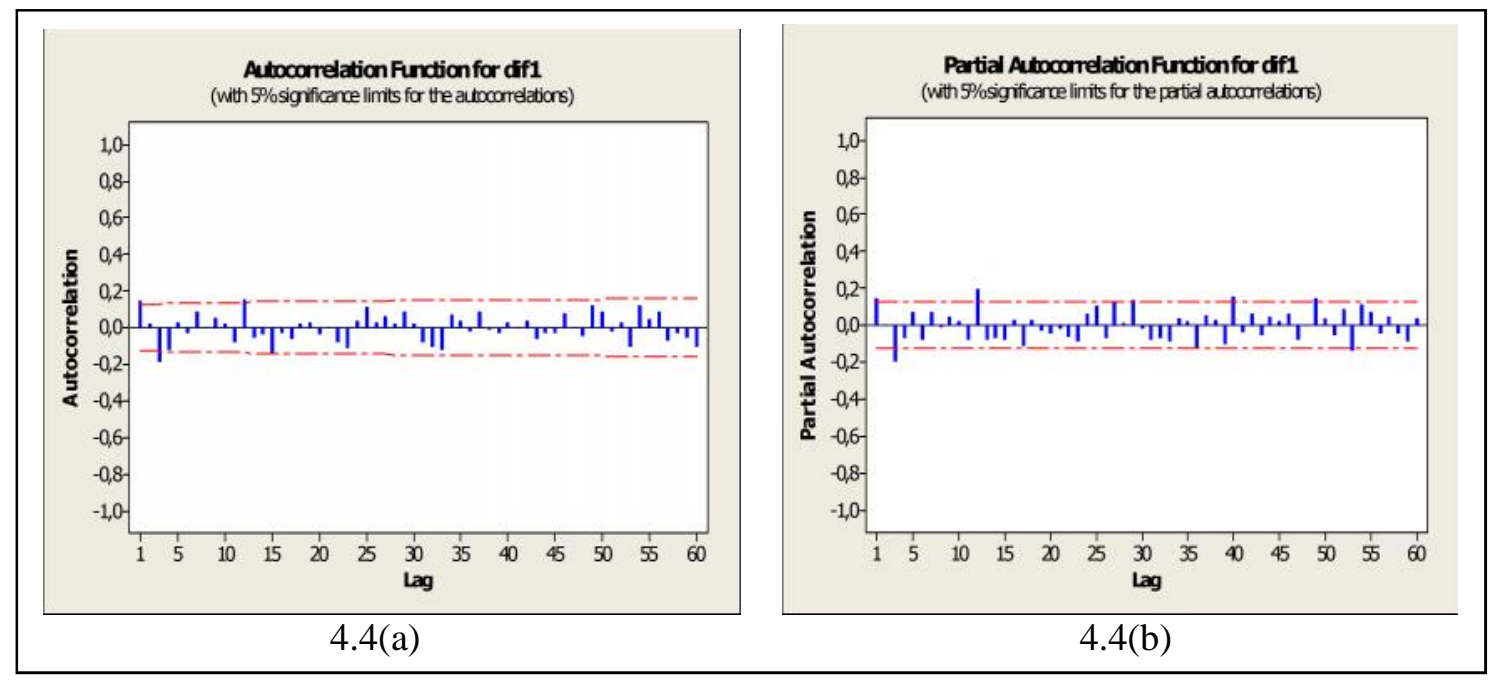

Gambar 4.4 Plot ACF dan PACF data IHSG setelah didifference 1 non musiman

Berdasarkan gambar 4.4, maka beberapa kemungkinan model ARIMA data IHSG dapat dilihat pada tabel 4.2. Berdasarkan tabel tersebut dapat diketahui bahwa semua parameter model signifikan pada $\alpha=5 \%$, sehingga dugaan modelmodel tersebut diikutkan pada langkah selanjutnya. 
Tabel 4.2 Estimasi Parameter Dugaan Model ARIMA

\begin{tabular}{ccccc}
\hline Model & Parameter & Koefisien & P-value & Kesimpulan \\
\hline $\begin{array}{c}\text { ARIMA } \\
(1,1,0)\end{array}$ & $\emptyset_{1}$ & 0,1421 & 0,032 & Signifikan \\
\hline ARIMA & $\emptyset_{1}$ & 0,1550 & 0,019 & Signifikan \\
$([1][12], 1,0)$ & $\emptyset_{12}$ & 0,1536 & 0,022 & Signifikan \\
\hline ARIMA & $\theta_{1}$ & $-0,1742$ & 0,008 & Signifikan \\
$(0,1,[1][12])$ & $\underline{\theta}_{12}$ & $-0,1822$ & 0,006 & Signifikan \\
\hline
\end{tabular}

Tabel 4.3 Uji Asumsi White Noise Residual

\begin{tabular}{|c|c|c|c|c|c|}
\hline Model & Lag & $\mathbf{1 2}$ & $\mathbf{2 4}$ & $\mathbf{3 6}$ & \multirow{2}{*}{ Kesimpulan } \\
\hline \multirow{2}{*}{$\begin{array}{c}\text { ARIMA } \\
(1,1,0)\end{array}$} & Chi-Square & 21,3 & 34,5 & 48,9 & \multirow{3}{*}{ tidak white } \\
& DF & 11 & 23 & 35 & noise \\
\cline { 2 - 6 } & $P$-Value & 0,031 & 0,058 & 0,060 & \\
\hline \multirow{2}{*}{$\begin{array}{c}\text { ARIMA } \\
([1][12], 1,0)\end{array}$} & Chi-Square & 15,73 & 31,47 & 48,39 & \multirow{2}{*}{ white noise } \\
\cline { 2 - 6 } & DF & 10 & 22 & 34 & \\
\cline { 2 - 6 } & $P$-Value & 0,107 & 0,086 & 0,052 & \\
\hline \multirow{2}{*}{$\begin{array}{c}\text { ARIMA } \\
(0,1,[1][12])\end{array}$} & Chi-Square & 14,26 & 28,39 & 45,26 & \multirow{2}{*}{ white noise } \\
\cline { 2 - 5 } & DF & 10 & 22 & 34 & \\
\cline { 2 - 5 } & $P$-Value & 0,161 & & 0,093 & \\
\hline
\end{tabular}

Dari tabel 4.3 diperoleh informasi bahwa hasil uji residual white noise didapatkan untuk model ARIMA $(1,1,0)$ tidak white noise karena pada lag ke-6 nilai $p$-value lebih kecil dari $\alpha=5 \%$. Sedangakan untuk model ARIMA ([1][12],1,0), ARIMA $(0,1,[1][12])$ memenuhi asumsi white noise residual. Selanjutnya adalah pengujian asumsi residual berdistribusi normal. Hasil pengujian menunjukkan bahwa model ARIMA ([1][12],1,0), ARIMA $(0,1,[1][12])$ mempunyai nilai $p$-value lebih besar dari $\alpha=5 \%$, sehingga memenuhi asumsi residual berdistribusi normal.

Pemilihan model terbaik dilakukan dengan melihat nilai MAPE, MSE dan AIC dari model ARIMA ([1][12],1,0), ARIMA (0,1,[1][12]). Hasilnya dapat dilihat pada tabel 4.4.

Tabel 4.4 Nilai MAPE, MSE dan AIC

\begin{tabular}{|c|c|c|c|}
\hline Model & $\begin{array}{c}\text { MAPE } \\
(\mathbf{\%})\end{array}$ & MSE & AIC \\
\hline ARIMA $([1][12], 1,0)$ & 1,18 & 3812,13 & 2485,75 \\
\hline ARIMA $(0,1,[1][12])$ & 1,30 & 3788,57 & 2484,36 \\
\hline
\end{tabular}

Berdasarkan tabel 4.4, maka dapat diketahui bahwa nilai MAPE, MSE dan AIC terkecil adalah model ARIMA $(0,1,[1][12])$, maka model terbaiknya adalah ARIMA $(0,1,[1][12])$, sehingga model matematisnya adalah sebagai berikut :

$$
Z_{t}=0,1741 a_{t-1}+0,882 a_{t-12}+a_{t}
$$

Setelah didapatkan model terbaik, maka selanjutnya adalah meramalkan data IHSG satu periode ke depan, yaitu bulan Januari 2014. Hasilnya dapat dilihat pada 
13) Forecasting Indeks Harga Saham Gabungan (Ihsg) Dengan Menggunakan Metode Arima

tabel 4.5. Tabel 4.5 menunjukkan bahwa data actual dan data ramalan semuanya terletak pada selang interval kepercayaan $95 \%$.

Tabel 4.5 Hasil Ramalan data IHSG

\begin{tabular}{|c|c|c|c|c|}
\hline Tanggal & Aktual & Ramalan & Batas Bawah & Batas Atas \\
\hline $02-01-2014$ & 4327,27 & 4273,01 & 4094,76 & 4454,79 \\
\hline $03-01-2014$ & 4257,66 & 4265,45 & 4039,83 & 4494,81 \\
\hline $06-01-2014$ & 4202,81 & 4267,83 & 3937,47 & 4601,44 \\
\hline $07-01-2014$ & 4175,81 & 4276,16 & 3915,71 & 4636,02 \\
\hline $08-01-2014$ & 4200,59 & 4269,62 & 3884,62 & 4657,17 \\
\hline $09-01-2014$ & 4201,22 & 4270,25 & 3858,40 & 4679,88 \\
\hline $10-01-2014$ & 4254,97 & 4273,67 & 3837,21 & 4704,86 \\
\hline $13-01-2014$ & 4390,77 & 4283,27 & 3783,99 & 4788,91 \\
\hline $15-01-2014$ & 4441,59 & 4283,27 & 3729,75 & 4838,65 \\
\hline $16-01-2014$ & 4412,49 & 4283,27 & 3703,49 & 4861,46 \\
\hline $17-01-2014$ & 4412,23 & 4283,27 & 3680,95 & 4886,02 \\
\hline $20-01-2014$ & 4431,57 & 4283,27 & 3616,52 & 4953,00 \\
\hline $21-01-2014$ & 4452,50 & 4283,27 & 3595,62 & 4973,12 \\
\hline $22-01-2014$ & 4477,49 & 4283,27 & 3575,95 & 4993,29 \\
\hline $23-01-2014$ & 4496,04 & 4283,27 & 3556,94 & 5013,03 \\
\hline $24-01-2014$ & 4437,34 & 4283,27 & 3539,83 & 5033,65 \\
\hline $27-01-2014$ & 4322,78 & 4283,27 & 3483,68 & 5090,87 \\
\hline $28-01-2014$ & 4341,65 & 4283,27 & 3465,14 & 5108,77 \\
\hline $29-01-2014$ & 4417,35 & 4283,27 & 3447,43 & 5126,72 \\
\hline $30-01-2014$ & 4418,76 & 4283,27 & 3430,11 & 5144,32 \\
\hline & & & & \\
\hline
\end{tabular}

\section{Simpulan}

Berdasarkan hasil analisis, maka dapat diambil kesimpulan, yaitu model ARIMA terbaik yang menggambarkan data IHSG adalah model ARIMA $(0,1,[1][12)$ dan hasil ramalan satu periode ke depan menunjukkan hasil bahwa nilai ramalan dan aktual data IHSG terletak dalam batas interval kepercayaan $95 \%$.

\section{DAFTAR PUSTAKA}

Astuti, S., 2012, Hukum Pasar Modal, http://sriastutighevi15.blogspot.com, tanggal unduh 3 April 2014.

Makridakis, dkk., 1999, Metode dan Aplikasi Peramalan, Edisi kedua, Binarupa Aksara, Jakarta.

Parsiyo, 2005, Indikator keberhasilan pembangunan, http://ppmkp.bppsdmp.deptan.go.id, tanggal unduh 3 April 2014.

Wei, W.W.S., 2006, Time Series Analysis Univariate and Multivariate Methods, Third Edition, Addison Wesley Publishing Company, Canada.

www. duniainvestasi.com 
